\title{
To personlige bøker fra Golden Gate Bridge
}

\author{
Av Kim Larsen
}

Kevin Hines er en av de få som har overlevet et selvmordsforsøk ved utsprang fra Golden Gate Bridge i San Fransisco da han som 19-åring hoppet fra broen i september 2000. I samme periode patruljerte politimannen Kevin Briggs Golden Gate Bridge og hadde som en av sine oppgaver å forsøke å overtale selvmordskandidater fra å hoppe. I løpet av de siste årene har begge skrevet svært personlige bøker om sin posisjon på hver sin side av rekkverket. Vi skal se på begge bøkene, men først en kort innledning om selvmordsaktiviteten på denne spesielle broen.

GOLDEN GATE BRIDGE i San Fransisco er verdens mest kjente «selvmordshotspot» (Bateson, 2012; Friend, 2003). Dette er symbolladede steder som tiltrekker seg selvmordsaktivitet. Eksempler er Empire State Building, Eiffeltårnet og Domen i Firenze, før fysiske barrierer giorde det umulig å utføre selvmord fra disse stedene. Golden Gate Bridge sto ferdig i 1937 og har en høyde på 75 meter. Det første kjente selvmordet skjedde kun litt over tre måneder etter åpningen, og til nå er det over 1600 dokumenterte selvmord fra broen. Antallet er sannsynligvis langt høyere fordi mange ikke blir funnet. Golden Gate Bridge har alle egenskaper som skal til for at et hotspot skal bli skapt; det er en vakker arkikektonisk konstruksjon i seg selv og ligger i naturskiønne omgivelser. Også selve navnet kan spille en rolle.
En studie av Seiden og Spence (1983/84) formidler godt hva et hotspot er. Mens alle har hørt om Golden Gate Bridge har de færreste hørt om Oakland Bay Bridge. Den ligger imidlertid i samme område. Mens Golden Gate Bridge knytter San Fransisco sammen med Marin County, knytter Oakland Bay Bridge San Fransisco sammen med Oakland (via Yerba Buena Island). Den stod ferdig seks måneder før Golden Gate Bridge, og er omtrent like høy. Broene er imidlertid forskjellige på den måten at det kun er Golden Gate Bridge som har adkomst via gangvei. Mange av selvmordene som utføres på disse broene skier ved at personer plutselig stopper bilen og kaster seg over rekkverket. Det er denne typen selvmord Seiden og Spence har forsket på. De var spesielt interessert i personer som hadde utført selvmord ved utsprang fra en av disse broene og hadde adresse i East Bay, og som dermed bodde nærmest Oakland Bay Bridge. Seiden og Spence undersøkte slike selvmord i perioden helt fra 1937 til og med 1971. Ved 115 tilfeller hadde hele 58 personer kjørt over Oakland Bay Bridge (som rent instrumentelt er like godt egnet) og utført selvmord fra Golden Gate Bridge i stedet! De fant ikke ett eneste eksempel på det motsatte; at noen hadde kiørt over Golden Gate Bridge og utført selvmord fra Oakland Bay Bridge.

Der er etter årelange diskusjoner med meget høy emosionell temperatur, nylig (sommeren 2014) vedtatt å bygge en selvmordsbarriere i form av et beskyttende «nett» under Golden Gate Bridge. Mange mener at Eric Steels film The Bridge (2006) om selvmordene fra Golden Gate Bridge har vært medvirkende til dette resultatet. Filmen bruker 


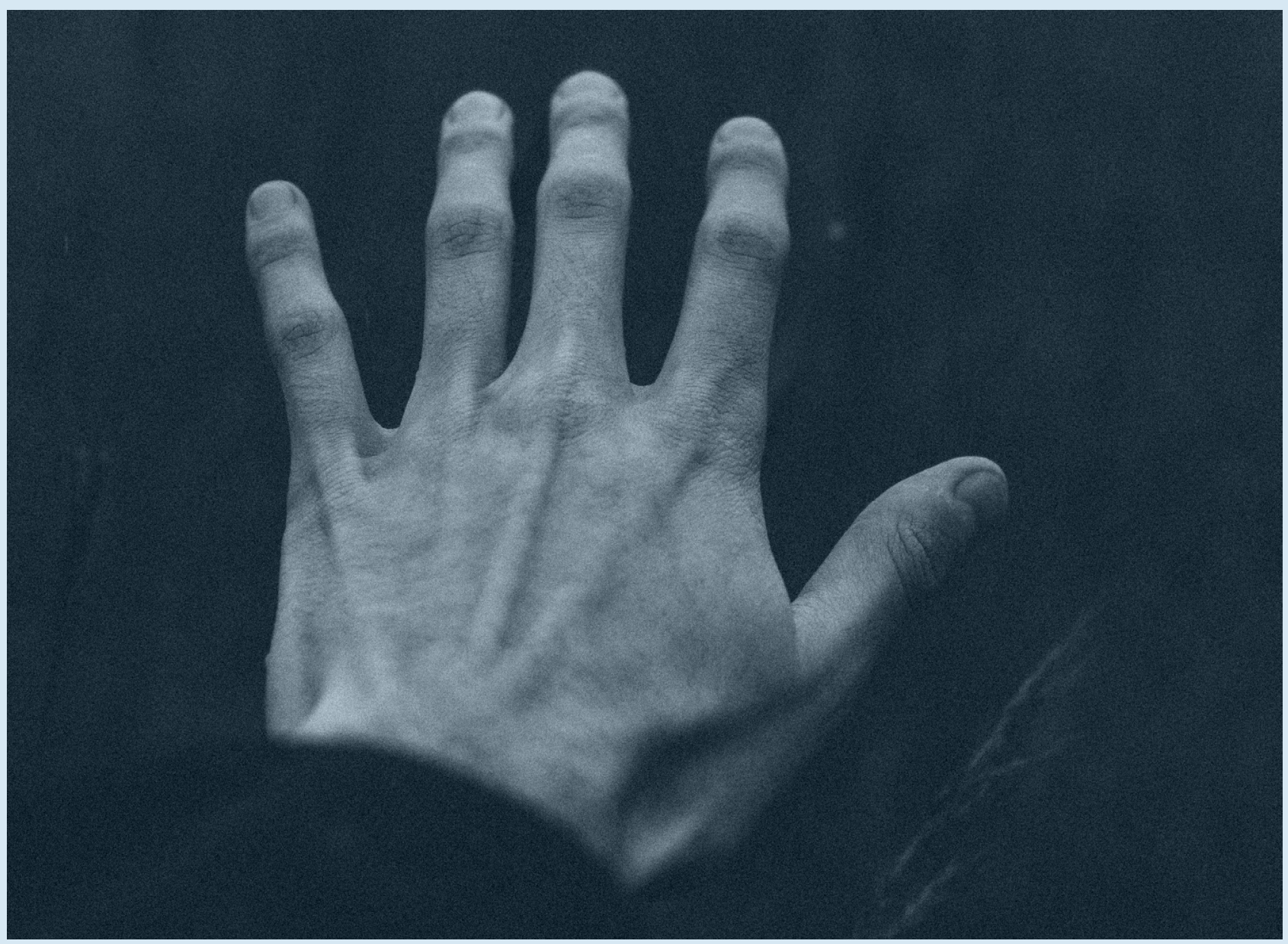

drastiske virkemidler; Steel filmet 23 av 24 selvmord som ble utført fra Golden Gate Bridge i 2004. Han fikk tillatelse til å filme under dekke av å lage en dokumentarfilm om broen. Steel interviuet etterlatte til de personene han hadde filmet. Filmen er svært kontroversiell og har da også forståelig nok vært behørig diskutert ut fra et etisk perspektiv. Det samme gielder også Iohn Batesons bok The final leap. Suicide on the Golden Gate Bridge (2012) hvor han blant annet trykker navnet til alle personer som har utført selvmord fra Golden Gate Bridge i et eget appendiks. Dette vil være svært kontroversielt i forhold til smittefaren.

Den vanlige oppfatningen er at effekten av selvmordsbarrierer vil være lav fordi de kommer for sent i selvmordsprosessen da personen «allerede har bestemt seg», og da vil komme til å utføre selvmord uansett (Miller, Azael \& Hemenway, 2oo6). Konsistente funn fra suicidologisk forskning indikerer overraskende nok det motsatte. Selvmordsimpulsen er som regel både ambivalent og fluktuerende; selv tiltak som kommer sent i den suicidale prosess «kjøper tid», og har effekt ved at selvmordsimpulsen kan forandre seg. Overraskende nok er det nettopp slike tiltak som begrenser tilgang til selvmordmetoder som er den type selvmordsforebyggende tiltak som er mest evidensbasert (se for eksempel Daigle, 2005; Gunnell \& Frankel, 1994; Mehlum, 2005 for gode oversikter her). Dette er imidlertid i strid med en commonsensisk oppfatning, derav også de nærmest evigvarende debattene om slike tiltak, og den emosjonelle temperatur som ofte karakteriserer dem. Retterstøl, Ekeberg \& Mehlum (2002) oppsummerer statistikken generelt på hvordan det går med dem som har utført et selvmordsforsøk slik: «Av mennesker som har giort selvmordsforsøk, vil i det lange løp 10-15 $\%$ senere dø i selvmord. Dette innebærer at det overveiende antallet likevel dør av andre årsaker» (s. 209-210). Begrunnelsen for å bygge selvmordsbarrieren på Golden Gate Bridge er statistikk som denne. Mer spesifikt er det også funnet at mange av de som har blitt forhindret fra å hoppe fra Golden Gate Bridge har en relativt lav gientakelsesfare på lang sikt (se Seiden, 1978 som forsket på akkurat denne gruppen). Nå kommer altså selvmordsbarrieren. Den har en estimert kostnad på 76 millioner dollar og vil ta tre år å bygge. (Se Whitmer \& Woods, 2013 for en kostnad-/nytteanalyse). 


\section{Cracked, not broken Surviving and thriving after a suicide attempt}

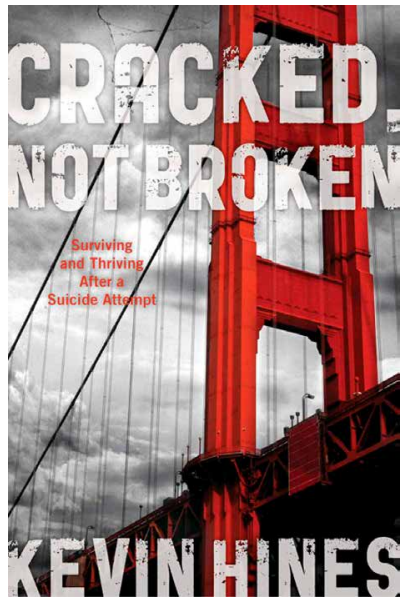

KEVIN HINES

Cracked, not broken. Surviving and thriving after a suicide attempt Plymouth: Rowman \& Littlefield. 2013 197 sider

ISBN: 978-1-4422-2240-3
KEVIN HINES HADDE det nærmest verst tenkelige utgangspunkt for sitt liv. Han er født av psykisk syke narkomane foreldre og blir etterlatt på slumhoteller uten tilsyn sammen med sin bror (som dør før han er fylt to år), mens foreldrene er ute på jakt etter narkotika. Barnevernet overtar forståelig nok etter hvert omsorgen og Kevin blir adoptert av en omsorgsfull og velstående familie. Kevin er annerledes enn de andre med rødt hår og fregner og opplever vedvarende mobbing på skolen. Han blir etter hvert med i bryting og amatørteater som han trives godt med, men opplever så å bli akutt psykotisk i ungdomstiden. Den psykiske lidelsen fører til uforståelig, skremmende og truende adferd som ytterligere bidrar til fremmedgiøring overfor omgivelsene. Sommeren 2000 opplever han at den personen han ser mest opp til, instruktøren i teatergruppen, plutselig utfører selvmord ved å skyte seg i hodet. Samtidig opplever Kevin at hans alvorlige psykiske lidelse (bipolar lidelse, type 1 rapid cycling med psykotiske innslag) får overtaket i hans liv. Han beskriver opptakten til det drastiske selvmordsforsøket ved at han opplever stemmer av degraderende og befalende karakter. Kevin klarer utad å fremstå som relativt upåfallende samtidig som planene om selvmord tar form. Han beskriver også hvordan han gleder seg til å dø, slik at han kan slippe unna effektene av sykdommen; uutholdelig angst, skrem-

\section{Disse partiene synes jeg er bokens beste; medrivende og skremmende lesning.}

mende vrangforestillinger og både visuelle og auditive hallusinasjoner. Han beskriver særlig de paranoide vrangforestillingene, hvor han er sikker på at hans nærmeste er forkledte representanter for en ond makt som kan komme til å drepe ham uten forvarsel. Han beskriver at han blir ledet til Golden Gate Bridge av stemmene:
You're a dead man! I hate you! You have no choice, I will kill you! If not today then eventually, I promise you - this is inevitable! You must die! You must die! (s. 52).

Han beskriver videre:

Why did I jump? The reason is quite simple. I believed I had to die. I believed I had no other option. I felt as though I was a burden to my family and friends. I had no origins I could accurately identify. I was not an athletic hero. I was not an actor. I believed I had nothing remarkable in my life. That was, of course, not the case. I had more than plenty to live for. Yet I had another piece of baggage - which I didn't know at the time. I had - and have - bipolar disorder (s. 3).

Kevin blir etter hoppet reddet opp av vannet av Kystvakten og innlagt på intensivavdeling. Han blir innledningsvis gitt femti prosents sjanse for å overleve. Kevin kommenterer det paradoksale i at han kort tid etter selvmordsforsøket 
både er redd for å dø av skadene og takknemlig for at han ble reddet. Han blir overført til psykiatrisk avdeling og står foran en lang rehabilitering, som somatisk sett går overraskende bra. Livet etter utskrivelsen er imidlertid ingen idyll; flere alvorlige psykotiske sammenbrudd medfører tre innleggelser på psykiatrisk avdeling i løpet av fire år. Ved ett av disse oppholdene treffer han sin fremtidige kone, som er der for å besøke en innlagt slektning. Hun blir senere angrepet av Kevin med hammer og golfkølle da han under en psykotisk episode tror at hun skal drepe ham. De psykotiske sammenbruddene blir godt formidlet på en skremmende realistisk måte. Det samme blir møtet med personalet i psykiatrien og medpasientene. Disse partiene synes jeg er bokens beste; medrivende og skremmende lesning. Kevin beskriver også godt den skammen han opplever etter de psykotiske sammenbruddene hvor han har satt sine nærmeste gientatte ganger i ytterst vanskelige situasjoner og såret dem på verst tenkelige måter.

Inspirert av en adoptivonkel som var medlem av Anonyme Alkoholikere og hadde sett verdien av at personer med store personlige problemer delte dem og snakket om dem med andre, holder Kevin noen foredrag om sine opplevelser; både om selvmordsforsøket og om sin psykiske lidelse. Han får umiddelbart feedback fra personer som hadde hørt foredragene om at de hadde vært medvirkende til at de ikke selv hadde utfort selvmord, og som også så opp til Kevin som en inspirasionskilde og et forbilde på hvordan man kunne leve med en alvorlig psykisk lidelse. Disse tilbakemeldingene giør at han opplever en dyp meningsfullhet ved å holde foredragene. Etter hvert «tar det helt av» og han havner til og med på Larry King Show, samt holder foredrag for politiet, psykiatrien og andre offentlige instanser. Han og adoptivfaren er begge aktive i foreningen som arbeider for byggingen av en selvmordsbarriere på Golden Gate Bridge.

Mot slutten av boken får jeg inntrykk av at Kevins foredrag om psykisk lidelse og selvmordsforsøk blir en primær kilde til meningsinnhold i hans liv. Jeg får noen ganger en litt urolig følelse når jeg treffer noen av brukerrepresentantene i psykiatrien; det virker på meg som de vever sitt livsinnhold rundt rollen som psykiatrisk pasient (gierne ledsaget av en aggressiv opposisjonsholdning til psykiatrien), og litt av den samme uroen får jeg mot slutten av denne boken. Jeg får en følelse av at Kevin ender opp primært med en identitet som psykiatrisk pasient og overlevende etter et selvmordsforsøk, og en sosial forankring av denne identiteten som følge av foredrag og medieopptredener. Dette kan medføre en rolle som også kan ha betydelige påkjenninger for ham selv. Det er han heldigvis også klar over:
If I were to die by suicide now, all of the people I have met, cared for, helped or loved would be crushed until the end of their lives. If I die by suicide now, what about the audiences with students and adults alike who have contemplated suicide, to which I have spoken about suicide prevention and staying mentally healthy? How would such an action affect their lives? They could potentially think, "If he couldn't live, then how can I?» That's dangerous. It is also a huge weight on my shoulders, but one I am prepared, willing, and able to carry. The people who have come up to me in every state or country in which I have spoken, and said, «I was going to kill myself, but because of you and your speech, now I will not», depend on me in some small way to stay alive and well. That is exactly what I plan to do, no matter how bad it gets or what mental breakdowns I experience from here on. I will stay alive. I will keep on keeping on» (s. 57).

Cracked, not broken. Surviving and thriving after a suicide attempt formidler godt hvordan det kan være å ha en alvorlig psykisk lidelse og hvordan den for Kevin stadig og uventet bryter inn i livet med forferdelige konsekvenser. Desto større blir da også beundringen for hvordan Kevin Hines har klart å bruke de lidelsene han har opplevd og sitt selvmordsfors $ø$ k til noe meningsfullt, både for seg selv og andre. 


\section{Guardian of the Golden Gate Protecting the line between hope and despair}

KEVIN BRIGGS ARBEIDET som politi i regionen som omfatter Golden Gate Bridge i 17 år. Han måtte ofte rykke ut til personer i suicidale kriser som var i ferd med å hoppe fra brua. Dødeligheten er på ca. 98 prosent. Den vanligste dødsårsaken er multiorgansvikt som følge av at ribben og ryggsøyle brekker og spidder hierte, lunger og andre organer. De som mot formodning overlever selve fallet vil drukne, både fordi de er så hardt skadet at de ikke klarer å svømme og fordi det er sterk strom i vannet. Lik er blitt funnet mange kilometer unna, delvis oppspist av diverse sjødyr. Mange blir aldri funnet.

Giennom trening i sitt arbeid ble Briggs etter hvert meget erfaren i å takle møtene med suicidale personer under disse drastiske omstendighetene, og har til sammen i sin karriere vært medvirkende til at over 200 personer har avbrutt selvmordsforsøket. Som en følge av sin yrkesmessige erfaring fikk han også interesse for selvmordsforebygging og psykiske lidelser, og ble etter hvert inter-

\section{Briggs har til sammen i sin karriere vært medvirkende til at over 200 personer har avbrutt selvmordsforsøket.}

viuet om dette i aviser og TV. Dette førte igien til at han ble engasjert som foredragsholder på kurs og konferanser. Briggs har også en personlig historie med tilbakevendende depresjon, og dramatiske hendelser i sin nærmeste familie. I sine foredrag integrerer han sin politifaglige erfaring med utrykningene ved selvmordskriser på Golden Gate Bridge med sin egen personlige historie. Briggs fikk tallrike tilbakemeldinger fra mennesker som hadde hørt foredragene hans (ikke minst via internett hvor mange av dem var tilgiengelige), og som mente at dette hadde vært avgiørende for at de selv ikke hadde utført selvmord. Oppildnet av disse tilbakemeldingene reiste

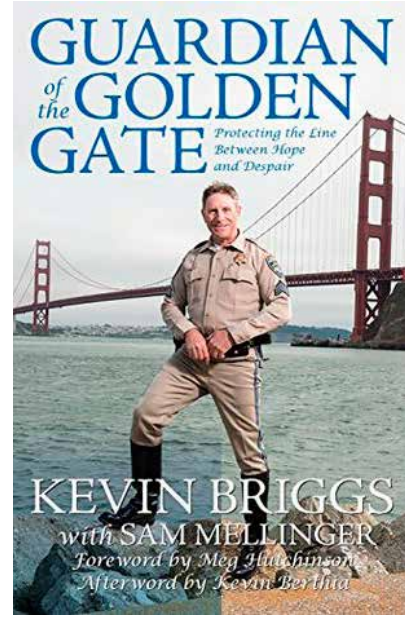

KEVIN BRIGGS

Guardian of the Golden Gate: Protecting the line between hope and despair.

Olathe: Ascend Books. 2015

304 sider

ISBN: 978-0-9904375-7-4
Briggs etter hvert verden rundt på kongresser og konferanser. Han gikk av med pension fra politiet i 2013 og skrev deretter denne boken.

Mesteparten av boken handler om selvmordsforebygging, men vi får også en biografisk fremstilling av forfatterens liv, som inneholder å bli diagnostisert med testikkelkreft som 21-åring og en livstruende ulykke under tjeneste som motorsykkelpoliti som 38-åring. Vi møter også historiene til noen av de personene Briggs var med på å redde i suicidale kriser, og personer han senere møtte under sin foredragsvirksomhet.

Fremstillingen dekker ulike fasetter av hans arbeide med selvmord og selvmordskriser. Et tankevekkende aspekt som ofte kommer i bakgrunnen er effekten av å bevitne et selvmord: «These bystanders just happen to be in the wrong place at the wrong time and see things that not only affect their day, but may even impact the rest of their lives. It's a hard thing for officers, but we're trained to see 
tragedy and choose this profession knowing we'll see some difficult things. Witnesses, however, don't get to make that choice" (s. 83).

Vi som arbeider i psykiatrien har som regel noen anamnestiske opplysninger før vi møter en person som setter oss i stand til å være litt forberedt på hva vi vil møte. Noen slik forhåndsinformasjon har ikke utrykningspersonalet, og Briggs er da også hypersensitiv på å tolke små cues i den suicidales kroppsspråk og fremtoning som for å sette sammen et større puslespill ut fra svært få biter. De viktige momentene er som forventet: empati, ro, langsomme bevegelser og en ikke-truende fremtoning, blikkontakt, unngå idylliserende kommentarer og urealistisk håp, holde samtalen i gang med nesten ethvert innhold for å skape en relasion og for å vinne tid, og heller ikke foreslå velmente og konkrete løsninger som kan virke fornærmende siden personen selv må kunne forutsettes å ha forsøkt en del løsninger forst. Mange av redningsaksionene finner sted i betydelig kulde og regn. Disse elementene er det ifølge Briggs også viktig at redningspersonalet eksponerer seg for. I tillegg vil en så lik klesdrakt som mulig utgiøre et ubevisst, subtilt empatisk bånd: «It is my common practice to try and dress similar to the person I am talking to over the rail. If they have a jacket on, then I can wear mine. If they don't, then I don't" (s. 34). . Det er noen triste observasioner også i forhold til hva utrykningspersonalet må ta høyde for, bilister som passerer stedet og oppfordrer selvmordskandidaten til å hoppe eller turister som tar bilder! Forfatterens beskrivelser av hopp han har bevitnet er godt egnet til å frata selvmord fra Golden Gate Bridge et romantisistisk skjær.

Vi treffer også noen av de personene Briggs er kommet i kontakt med i ulike faser av sin karriere og deres historier. Vi møter også et ektepar som mistet en sønn i selvmord, som eksempel på hvor massivt og vedvarende et selvmord kan endre de etterlattes liv. Denne sønnen var en av de personene som Briggs hadde forsøkt å redde, men forgieves. Briggs er i denne sammenhengen veldig klar på at en som profesionell kan ha giort jobben godt selv om resultatet blir tragisk. De historiene vi får presentert omhandler et bredt spekter av personer; fra den bostedsløse heroinavhengige som måtte tigge penger til bussen for å komme seg til Golden Gate Bridge til den søkkrike direktøren for et ekspanderende IT-selskap. Men fellestrekket mellom historiene er at liv som personene betraktet som helt håpløse og uopprettelige kunne utvikle seg til å bli rike og meningsfylte. I tillegg til viktigheten av denne type selvmordsforebygging ved utrykninger betoner også Briggs viktigheten av informasjon og åpenhet rundt psykiske lidelser.

Briggs' erfaring med selvmordsforebygging under svært vanskelige forhold er imponerende og hans formidling av lærdommen fra disse aksjonene og hans senere møter med suicidale personer under sin foredragsvirksomhet er vel verd å lytte til. Boken pulserer også

\section{Boken pulserer også med en dyp menneskelig varme og ærlighet. Dette er en bok som formidler håp.}

med en dyp menneskelig varme og ærlighet. Dette er en bok som formidler håp. Både i mine samtaler med etterlatte og ved studier av faglitteraturen har jeg lagt merke til at politiet blir omtalt giennomgående positivt av etterlatte, til tross for at den situasjonen de møter etterlatte i er emosjonelt og relasionelt svært krevende. Det er noe en kan forstå når en leser denne boken. Vi møter et menneske som har utfort konkret selvmordsforebygging under forhold de færreste av oss vil misunne ham, og som viser en imponerende kombinasion av profesjonalitet og menneskelig nærvær og varme.

\section{REFERANSELISTE}

Bateson, I. (2012). The final leap. Suicide on the Golden Gate Bridge. London: University of California Press.

Daigle, M.S. (2005). Suicide prevention through means restriction: Assessing the risk of substitution. A critical review and synthesis. Accident Analysis and Prevention, 37, 625-632.

Friend, T. (2003). Jumpers: The fatal grandeur of the Golden Gate Bridge. The New Yorker, 13. oktober.

Gunnell, D. \& Frankel, S. (1994). Prevention of suicide: aspirations and evidence. British Medical Journal, 308, 1227-1233.

Mehlum, L. (2005). Forebygging giennom begrensning av tilgangen til selvmordsmidler. Suicidologi, 10, 3-7.

Retterstøl, N., Ekeberg, 0 \& Mehlum, L. (2002). Selvmord - et personlig og samfunnsmessig problem. Oslo: Gyldendal Akademisk.

Miller, M., Azrael, D. \& Hemenway, D. (2006) Belief in the inevitability of suicide: Results from a national survey. Suicide and Life-Threatening Behavior, 36, 1-11.

Seiden, R.H. (1978). Where are they now? A follow-up study of suicide attempters from the Golden Gate Bridge. Suicide and Life-Threatening Behavior, 8, 203-216.

Seiden, R.H. \& Spence, M. (1983/1984). A tale of two bridges: Comparative suicide incidence on the Golden Gate and San Fransisco - Oakland Bay bridges. Omega, 14, 201-209.

Steel, E. (2006). The Bridge. IFC Films. (DVD utgave: Koch Lorber Films, 2007).

Whitmer, D.A. \& Woods, D.L. (2013). Analysis of the cost effectiveness of a suicide barrier on the Golden Gate bridge. Crisis, 34, 98-106. 